\title{
LA COMPETENCIA MESTIZA. Chicago bajo el trópico o las
virtudes heurísticas del mestizaje
}

ELISABETH CUNIN

IRD, FRANCIA

Elisabeth.Cunin@bondy.ird.fr

\begin{abstract}
Resumen
RADICIONALMENTE, LOS INVESTIGADORES ESTADOUNIDENSES QUE SE HAN INTERESADO POR América latina y el Caribe identifican en sus análisis sobre el mestizaje un continuum racial, una armonía en las relaciones interétnicas, que contrasta con la bipolarización y el conflicto que las caracteriza en Estados Unidos. Esta imagen idealizada del sur del continente, sin embargo, esconde la permanencia de una organización socio-racial muy discriminatoria, heredada del periodo colonial. A partir de la relectura de la producción de los investigadores de la tradición de Chicago (Park, Hughes y Goffman, principalmente), la autora se pregunta por el alcance de sus conceptos, reinterpretados a la luz del reconocimiento a la multiculturalidad en América latina y el Caribe, particularmente en Brasil y Colombia, proponiendo su propia perspectiva de análisis para adentrarnos en la comprensión de los mecanismos de la transición -si es que acaso la hubo- entre mestizaje y multiculturalismo.
\end{abstract}

PALABRAS ClAVE: mestizaje, discriminación racial, multiculturalismo, Brasil, Colombia.

\section{Abstract}

N tHEIR ANALYSES ON MisCEGENATION OR MESTIZAJE IN LATIN AMERICA AND tHE CARIbbean, North American researchers have traditionally identified a "racial" continuum, a harmony of interethnic relations contrasting with the bi-polarization and conflict that characterizes them in the United States. This idealized image of the southern part of the continent hides nevertheless, the permanence of a strong discriminatory socio-racial organization inherited from the Colonial period. The author, through a re-reading of the Chicago sociological tradition (Park, Hughes and Goffman), questions the scope of their concepts, reinterpreting them in the light of Latin America and the Caribbean's recognition of multiculturalism, particularly in Brazil and Colombia. She proposes her own analytical perspective for understanding the mechanisms for the transition-if there ever was one-from mestizaje to multiculturalism.

KEY WORDS: Mestizaje, racial discrimination, multiculturalism, Brazil, Colombia.

Revista Colombiana de Antropología

Volumen 38, enero-diciembre 2002, pp. II-44 


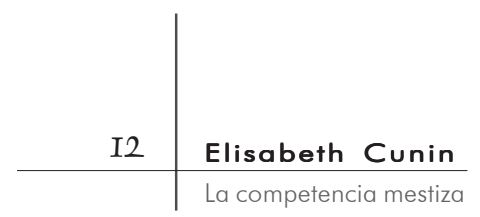

\section{INTRODUCCIÓN}

Г N LA AMÉRICA COLONIAL, El MESTIZAJE SE PERCiBÍA COMO UNA AME- naza permanente: amenaza biológica frente a una concepción - europea de pureza y de jerarquía entre las razas; amenaza cultural frente a todo tipo de sincretismos; amenaza política frente a la potenciación de las reivindicaciones y de las pretensiones de los mestizos; amenaza social, en fin, frente a la disolución de todo principio de organización, en particular el de la distinción entre las castas ${ }^{1}$. Lo que preocupaba no era tanto el esclavo sino el libre de color, que pervertía tanto el orden social -ni amo ni esclavo- como el racial -ni blanco ni negro-, por su posición intermedia, entre dos. Confundiendo la superposición entre estos dos órdenes, a pesar de las tentativas de regulación jurídica, el mestizaje -lejos de obedecer a una lógica de armonía y de pacificación- alimentó y acentuó el recurso a la ideología racial y al prejuicio del color (Bonniol, I990).

Al pretender explicar la razón de ser del mestizaje se experimenta una suerte de impotencia: existe un malentendido inherente a los análisis sobre el mismo (Bouysse-Cassagne, I994: III); la palabra mestizaje se "presta para confusión" (Bernand y Gruzinski, I993: 8); este se construye sobre una asimilación entre lo social y lo biológico ${ }^{2}$ (Benoist y Bonniol, I994). Su comprensión se opone a nuestras costumbres intelectuales, que tienden a preferir los conjuntos monolíticos a los espacios intermedios y la rigidez de las categorías a los "intersticios sin nombre"

I. En este sentido, la imagen encantada del mestizaje tal como se transmite hoy -valoración de los intercambios culturales, modernidad de los matrimonios mixtos, interpenetración de las sociedades, etcétera- es una construcción occidental y contemporánea.

2. "El discurso científico recupera entonces un objeto definido por la percepción colectiva, que cree ser un objeto biológico, mientras que el mestizaje expresa la imagen de una diferencia morfológica, imagen que fluctúa según la conveniencia del sentido social otorgado a esta diferencia" (Benoist y Bonniol, 1994: 65. Subrayado por los autores).
(Gruzinski, I999: 42).

Recientemente, en un seminario organizado por la Universidad Nacional de Colombia, cuyo título era "¿Mestizo yo? Diferencia, identidad e inconsciente" (Figueroa Muñoz y San Miguel, 2000), se subrayó la dificultad de comprender el mestizaje en expresiones tales como: "las complicaciones del mestizaje" (Ibídem: IO), el "no lugar" del mestizo (4I), la "lógica perversa” del mestizaje (6o). Así, las tentativas de su aprehensión teórica (Laplantine y Nouss, 1997) llegaron a definir el concepto de manera negativa, es 


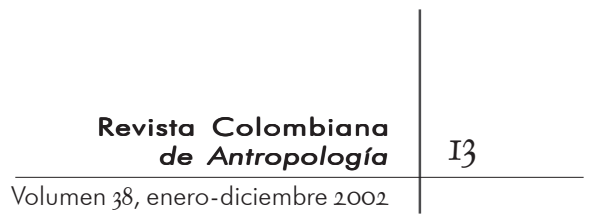

decir, partiendo de lo que no es el mestizaje: no es fusión ni fragmentación; contradice la polaridad homogéneo/heterogéneo; lo más opuesto al mestizaje no es únicamente lo simple, lo puro, lo separado, sino también la totalidad, la fusión, el sincretismo, que suponen la existencia de elementos ontológicamente distintos. Incluso se ha llegado a denunciar el "fantasma" y la "trampa" del mestizaje (Amselle, 1999; 2000), aun cuando, antes, se hubiera defendido el estudio de "lógicas mestizas" (Amselle, 1990).

Ahora bien, relegar el mestizaje a un desequilibrio transitorio o desterrarlo del campo científico significa privarse de introducir la ambivalencia y la infinitud en el seno mismo del pensamiento científico, concibiéndolo sólo en términos de debilidad, renuncia o fracaso. Negación de la identidad y de la alteridad, el mestizaje obliga a pensar lo distinto que no está tan lejos, y lo lejano, que no es tan distinto. Aparece como un proceso que pone en duda cualquier tentativa de clasificación social y científica, como una práctica subversiva de todas las categorías. E incita a no seguir aislando lo negro de lo blanco, la identidad de la alteridad; para ello, hay que emplear la y en lugar de la $o$, la coexistencia en el de la distinción, y situarse en la frontera, en el vaivén. El problema no se revela únicamente en referencia a una crisis de la identidad, sino también como una crisis de la lógica misma de la identidad (Laplantine y Nouss, 1997: 27I).

En este artículo quisiera mostrar que el mestizaje, no a pesar de las imprecisiones y de las ambigüedades señaladas por quienes lo han estudiado, sino gracias a ellas, es un objeto pertinente y una herramienta heurística del análisis sociológico y antropológico, que lleva a una reflexión sobre la construcción de las categorías sociales y científicas ${ }^{3}$.

Con este objetivo me he ubicado en 3. Estudiar el mestizaje implica, además, unos principios metodológicos, en particular en cuanto a la objetivación de la práctica del investigador, una ambición tan ilusoria como reductora. Sin embargo, como la explicitación crítica de la experiencia en el terreno es inseparable del proceder científico, este tema no será abordado en este artículo.

4. Este texto se refiere, fundamentalmente, a dos países, Brasil y el contexto de la afirmación del multiculturalismo en varios países sudamericanos ${ }^{4}$ en los años I980I990, que, por primera vez, reconocieron la existencia de "poblaciones afro-americanas", concediéndoles unos derechos específicos (Arocha, 1992; Uribe y Restrepo, I997; Agier y Hoffmann, I999). Si el mestizaje había significado homogeneidad e invisibilidad, desde entonces ha permitido la afirmación de las diferencias y la valorización de las especificidades étnicas. 


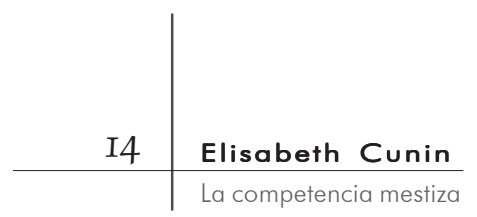

- Colombia, cuyas historias se han distinguido por la importancia de los mestizajes y que, recientemente, han formulado legislaciones especialmente innovadoras en lo referente al reconocimiento de la plurietnicidad. En general, estos análisis tienen eco en otros países latinoamericanos y caribeños que han sido marcados por el sistema esclavista. Para el caso de las Antillas francesas, véase Bonniol (I992); para Venezuela, Charier (2000). delo "bi-racial" en Estados Unidos y uno "multi-racial" en Latinoamérica (Spickard, 1989; Davis, I991; Skidmore, I993).

Ahora bien, resulta interesante revisar la posición de los investigadores de la tradición de Chicago, quienes iniciaron los estudios sobre las relaciones raciales e interétnicas en el sur del continente. Veremos entonces que, desde Park hasta Goffman, pasando por Hugues, las herramientas más pertinentes para el estudio del mestizaje -hombre marginal, dilema del estatus, distinción estigmatizado/estigmatizable- no han sido aplicadas en América latina. De este modo, mostraremos cómo los impases conceptuales y las contradicciones prácticas a las que conduce el mestizaje poseen virtudes heurísticas, especialmente con la introducción de la noción de "competencia mestiza".

\section{Precisiones sobre}

\section{LOS TERMINOS CONCEPTUALES}

H N PRIMER LUGAR, ES NECESARIO HACER UNA PRECISIÓN EN TORNO AL $\sqcup$ término raza, ampliamente utilizado en América latina y en Estados Unidos, pero que ha sido excluido del lenguaje científico y del cotidiano en Francia. El investigador que estudia el papel de las razas y los mecanismos del mestizaje se enfrenta con una paradoja que fundamenta su reflexión: las razas no existen. Más exactamente, el término remite a un objeto que no existe pero que se vuelve una realidad por su sola designación, dando lugar a prácticas sociales que efectivamente existen (Guillaumin, 1992). En consecuencia, en este artículo la raza no se considerará una categoría analítica sino práctica, social y política, determinada por la existencia hipotética de diversas razas 


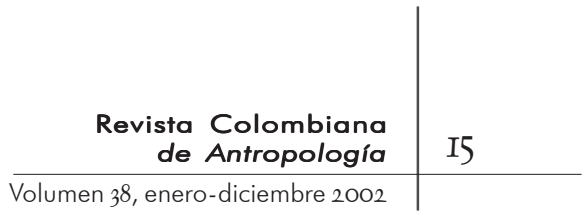

(Brubaker, 200I). Demostrar la inexactitud del término -ya sea que provenga de las ciencias sociales o de las naturales- no basta para que dejen de existir las actividades sociales en que se manifiesta, sean cognitivas o prácticas; además, la confusión entre su acepción popular y científica constituye una dimensión intrínseca de esta categoría (Wacquant, 1997), y es igualmente un objeto de investigación. Es por esto que haré referencia a la noción de raza escribiéndola en itálicas, pues sólo así podrá recordarse que, lejos de ser un vocablo del lenguaje científico, esta noción remite a un proceso de construcción emic de la clasificación del otro.

El investigador no puede aprehender la raza como un atributo de los individuos o de los grupos, que podría ser descubierto, descrito y definido: la raza es una categoría popular por medio de la cual se descifra e interpreta el entorno social, el pasado y el presente, dándole sentido a las prácticas cotidianas y permitiendo evaluar y clasificar al otro. Sólo los procesos sociales mediante los cuales se producen, conocen y adoptan las categorías prácticas constituyen un objeto para una investigación que no se ubica únicamente del lado del constructivismo -fluidez, multiplicidad de las identidades- sino que tiende también a comprender los mecanismos de cristalización de las prácticas identitarias. En este artículo estudiaré los contactos entre personas de diferente raza, concebida como una categoría socialmente operativa, a partir de criterios biológicos -color, rasgos fenotípicos-. La raza será considerada como un "discriminante de rol" (Hannerz, I980), un "marcador de identidad" (Bonniol, I992), un condicionamiento exterior al conjunto de los compromisos individuales.

Contrario a los análisis esencialistas de la raza, la etnicidad y la identidad que inspiraron los primeros trabajos colombianos -en la búsqueda de "huellas de africanía" y de "comunidades negras"- que naturalizan la alteridad, definida en términos físicos o culturales, me interesaré por los mecanismos dinámicos e interactivos de elaboración y consolidación de las fronteras entre ellos y nosotros o incluso, de emergencia y de fijación de las normas sociales.

Por esta razón no cederé al uso corriente que transforma una apariencia aproximada y socialmente construida en una categoría para la cual el sustantivo, escrito con mayúscula, supone la idea de una identidad que sería natural e incuestionable (Agier, 


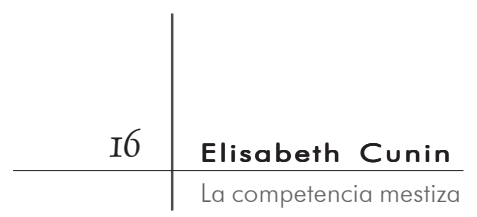

5. En las citas y referencias se conserva la presentación propuesta por el autor.

6. En el sistema de castas, el término mestizo en español, y caboclo en portugués, remiten al cruce entre blanco e indígena; mulato -en español y en portugués- es el cruce de blanco y de negro; zambo en español, cafuso en portugués, es el de indígena y de negro -en español los descendientes de blanco y mestizo, blanco y mulato, indígena y mestizo, indígena y mulato, etcétera, corresponden a su vez a categorías administrativas: cuarterones, tercerones, salto atrás, etcétera-. El término moreno remite al uso popular que permite atenuar la identificación del negro. Utilizaré los términos mestizo y mestizaje en su sentido genérico de combinaciones múltiples, sin juzgar de antemano la pertenencia racial de los individuos, y no como sinónimos de descendientes de indígena y blanco.

socialmente construidas de los hechos y de los individuos.
2000: 8). Contra esta escritura consensual ${ }^{5}$ -que se expresa además en la sustitución del negro por el afroamericano, del indio por el indígena-y políticamente correcta, que paradójicamente contribuye al mantenimiento de una visión esencialista de la raza, emplearé sin mayúscula los términos negro, blanco y sus derivados -mestizo, mulato ${ }^{6}$, etcétera-. Estos términos serán matizados de manera relativa entre más/menos negro y más/menos blanco. Se trata, primero que todo, de analizar cómo la apariencia racial interviene en los mecanismos de la identificación de sí mismo y de los otros, más que de buscar una supuesta identidad negra, blanca o mestiza. En otras palabras, ni la raza ni la etnicidad serán vistas como atributos de personas o grupos, sino como actividades cognitivas y prácticas por medio de las cuales los actores realizan descripciones

\section{LA ESCUELA DE CHICAGO EN AMÉrica LATINA}

$F$ i L DESAFÍO DEL MESTIZAJE NO ES SÓLO UN PROBLEMA DE OBJETO: ¿qué es el mestizaje? Hay, además, un problema en las herramientas intelectuales: ¿cómo pensar el mestizaje? ¿Cómo hicieron los investigadores provenientes de la tradición de Chicago, con los instrumentos que elaboraron frente al estudio de relaciones raciales antagónicas, para aprehender el mestizaje como la disolución de las categorías de pertenencia? Aquí, me interesaré en dos casos: el primero, ampliamente conocido es la mirada por parte de Chicago sobre el sur del continente; el otro, menos estudiado, es la asimilación del mestizo al hombre marginal. 


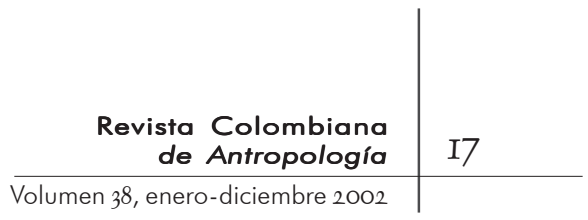

\section{De Chicago a Bahía}

C n lOS ESTUdios SOBRE LAS POBLACIONES NEGRAS Y SOBRE LAS RELA$\sqcup$ ciones interétnicas en general, suelen distinguirse América del norte y del sur: la primera se caracteriza por fuertes divisiones y un estado de conflicto recurrente; la segunda, por un mestizaje generalizado y la armonía en las relaciones sociales. De un lado, evocaremos los análisis producidos en la denominada escuela de Chicago, según la expresión de Howard Becker ${ }^{7}$ (I998), que llegan al paradigma del gueto negro; del otro, mencionaremos las propuestas de Vasconcelos (I992) en el caso de México y su noción de "raza cósmica", o las de Gilberto Freyre (I997), que habla de "democracia racial” en Brasil. En Estados Unidos, esta situación ha sido descrita en términos de violencia y segregación, mientras que en América latina mediante los de relaciones pacíficas, de integración y de homogeneización ${ }^{8}$.

Sin pretender una comparación entre Chicago y Bahía, Cartagena o Caracas, y menos ignorar los análisis realizados desde principios de siglo al norte o al sur del continente $^{9}$, consideraré a la escuela de Chicago como portadora de los paradigmas fundadores de los estudios sobre las relaciones raciales. No se trata de aplicar Chicago en América latina o de presentar un análisis de la sociedad estadounidense, sino de franquear las barreras nacionales y académicas, acceder al recurso de la desviación para entender así el alcance de los conceptos formulados por los investigadores de Chicago y lograr, finalmente, cuestionar la singularidad latinoamericana.

Esta comparación la han realizado implícitamente los propios actores cuando se preguntan -en especial después de la introducción del multiculturalismo en países

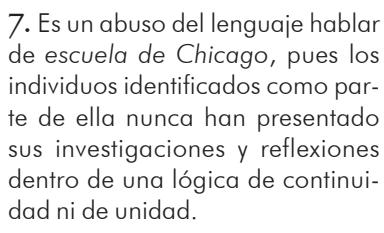
de escuela de Chicago, pues los individuos identificados como parte de ella nunca han presentado sus investigaciones y reflexiones dentro de una lógica de continuidad ni de unidad.

8. Esta divergencia se explica, además, por la existencia de orientaciones disciplinarias propias de norte y del sur del continente: en Estados Unidos, las poblaciones negras son estudiadas desde una perspectiva sociológica (Du Bois, I899; Frazier, I949; Park, I950), en virtud de la cual los investigadores privilegian el análisis de los procesos de desorganización/reorganización ligados a la urbanización y, más allá el de la asimilación -con excepción de los trabajos de M. J. Herskovitz-. Entre tanto, en América latina las poblaciones negras se constituyen en objetos de estudio para los antropólogos, que enfatizan sobre la aculturación, el sincretismo, la conservación o la desaparición de las tradiciones africanas.

9. En el contexto latinoamericano, donde el multiculturalismo se encuentra valorizado, los trabajos actuales tienden a afirmar la permanencia del racismo y el mantenimiento de relaciones raciales desiguales, contrastando con los análisis en términos de armonía racial y de invisibilidad de las poblaciones negras. Para el caso de Brasil, véanse Lovell (1994); Véran (1999); Agier (2000). Para Colombia: de Friedemann (I993); Uribe y Restrepo (1997); Wade (1997); Agudelo (1999). 


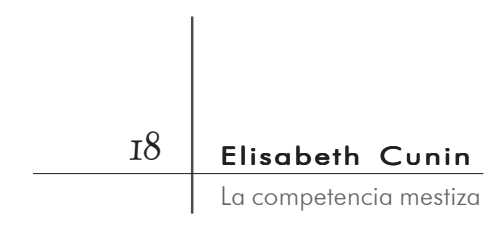

como Colombia, Brasil, Ecuador o Venezuela- por la definición del afroamericano; permite, además, releer los conceptos fundadores de las ciencias sociales estadounidenses, en términos de relaciones raciales, a la luz de la situación sudamericana. Esto era lo que hacía Roger Bastide en su análisis de la situación brasilera a partir de conceptos desarrollados en Estados Unidos: gueto, casta/clase (Bastide, I996). Fue lo mismo que hicieron varios investigadores estadounidenses cuando trabajaron en Latinoamérica sobre los contactos entre personas consideradas diferentes por su raza: Robert Park (1950), Charles Wagley (1968), Marvin Harris (I965), etcétera.

¿Qué dicen los investigadores de Chicago sobre las relaciones raciales en América latina? Me interesaré particularmente en los trabajos de Donald Pierson ${ }^{10}$, discípulo de Park -que, entre otras cosas, realizó la introducción de su obra principal- lle-

IO. Véanse, principalmente, Pierson (1967 y 1972). vados a cabo en Salvador de Bahía. Pierson recuerda que su método se inscribe dentro del continuum teórico de las re-

flexiones realizadas sobre las relaciones raciales en Estados Unidos, y confiesa su deseo, característico de la época, de extender el horizonte geográfico de esos estudios:

En I934, siendo asistente de sociología en la universidad de Chicago, el doctor Herbert Blumer me llamó la atención sobre las posibilidades que ofrecía Brasil como terreno de estudio de los contactos raciales y culturales, y además los doctores Robert Redfield, Louis With y Ellsworth Faris me llenaron de coraje para considerar seriamente estas posibilidades (...). Por la misma época, el Dr. Robert Park regresaba de un prolongado viaje alrededor del mundo, durante el cual había observado de cerca un buen número de centros de contacto social y cultural, incluido el Brasil (Pierson, I967: xii).

Para Pierson, y he aquí la tesis central de sus estudios, los conflictos en Bahía toman la forma de antagonismos de clases y no de antagonismos raciales (Pierson, 1967:349). En la introducción a la segunda edición, en I965-la primera edición de su obra sobre Bahía data de 1942-, Pierson confirma lo que había dicho: existe una tendencia a ver un conflicto racial, o al menos de color, en situaciones en las que se pone en juego la competición entre clases (Pierson, 1967: xiii).

Tal divergencia entre América del norte y del sur se explica, antes que nada, por la definición diferencial de las categorías 


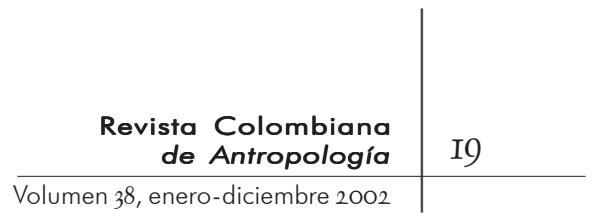

raciales, por el estatus acordado al negro y al blanco. Si en Estados Unidos sólo pueden pensar en blanco y negro, en Brasil se tiende, en cambio, a no verse ni en blanco ni en negro. Así, a la representación dicotómica del todo o nada se contrapone un continuum encarnado en el mestizaje. De un país al otro es imposible emplear los mismos términos:

\begin{abstract}
En Estados Unidos, "blanco" significa 'de descendencia caucásica pura’; por otra parte, en Brasil, 'branco' quiere decir 'una persona predominantemente blanca, independientemente de su origen racial', esto incluye a millares de mestizos de piel clara y, en el caso de los individuos que poseen signos de prestigio, los mestizos oscuros y ocasionalmente también un negro. Otras veces llega a significar simplemente 'una persona con prestigio' o simplemente 'mi amigo'. En el caso del 'Negro', en Estados Unidos significa 'descendiente de africano en cualquier grado, incluyendo a todos los mestizos' (el origen es el referente); mientras que en Brasil un 'préto' puede señalar a 'una persona con rasgos Negroides evidentes', ocasionalmente a 'una persona de poco estatus', o simplemente a 'un enemigo personal' (Pierson, I967: xxiv. Subrayado por el autor).
\end{abstract}

En otras palabras, la famosa regla estadounidense de la gota de sangre no significa nada en Brasil ni en América latina en general, puesto que las categorías de blanco y negro remiten a la apariencia física y al estatus social, pero no a una supuesta pertenencia racial, entendida como una ascendencia genética. El blanco y el negro corresponden a posiciones sociales, de tal manera que la movilidad ascendente puede manifestarse con una salida de la categoría del color. Así, al sustituir al negro por el mestizo, en Brasil se suprimirían las barreras raciales.

En su análisis, Donald Pierson se basa en tres diferencias históricas entre América del norte y América del sur, para él determinantes.

I. Esclavitud y manumisión. Pierson considera que en Brasil la esclavitud reposaba en lazos de familiaridad, impensables dentro de la concepción biologizante estadounidense. Él antepone el fundamento exclusivamente racial del sistema esclavista de Estados Unidos al caso brasilero que, aun cuando reposa en un principio de diferencia racial, se inscribe antes que nada en una lógica del derecho de propiedad y de prosperidad económica. En general, los análisis consideran que el 


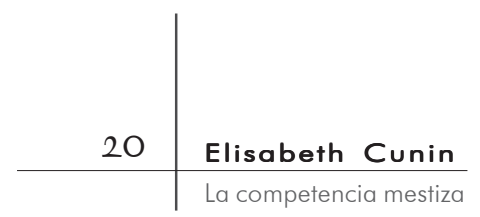

sistema esclavista de origen español fue menos severo que el instaurado en los países anglosajones (Degler, 1971; Cabellos Barreiro, I99I: 19-20; Sala-Moulins, I992; Jaramillo Uribe, I994: I72); en cualquier caso, está determinado por la importancia del fenómeno de manumisión, que autorizaba la liberación legal de esclavos. Esto muestra hasta que punto el esclavo era considerado una mercancía, pero también un capital económico, que podía cederse a título de una compensación financiera. Según Pierson, el sistema esclavista latinoamericano no está fundado del todo a partir de una ideología de la diferencia racial, sino de la búsqueda de rentabilidad económica.

2. De la competición al paternalismo. A diferencia de lo que sucedió en el sur de Estados Unidos, la abolición de la esclavitud en Brasil no generó una ruptura violenta en la estructura social (Pierson, I967: 346-347). Fue más el producto de una transición progresiva que, sin cuestionar los lazos existentes y evitando la instauración de un sistema de castas alrededor de una línea de color (color line), favoreció la conservación de las relaciones heredadas de la época esclavista. En Estados Unidos el problema de las relaciones violentas entre las razas surgió al mismo tiempo que la migración de la población negra del sur hacia las grandes ciudades del norte, con el nacimiento de una clase media negra y con el aumento del nivel educativo de las poblaciones negras. Listos para competir por sus propios lugares, se convirtieron en una amenaza para los blancos. En Bahía no tuvo lugar ningún proceso similar a este, como tampoco ningún ciclo de relaciones raciales. Su población negra no proviene de una migración reciente. De manera que, siguiendo las reflexiones de Donald Pierson, el problema de las relaciones raciales no ha sido planteado: cada uno tiene su lugar, cada uno actúa según lo que se espera de él, las normas comunes se conocen y aceptan y, por tanto, la competición entre poblaciones blancas y negras no tiene razón de ser, o si existe no se expresa en términos raciales.

Los estudios estadounidenses establecen distinciones entre dos situaciones muy diferentes: la del sur de Estados Unidos, donde incluso después de la desaparición de la esclavitud reina un sistema al mismo tiempo discriminante y normalizado, regulado por el respeto a la etiqueta, para retomar el título del libro de B. W. Doyle (I937); y la de las ciudades del norte, caracterizadas por la libertad individual y la posibilidad de movilidad 


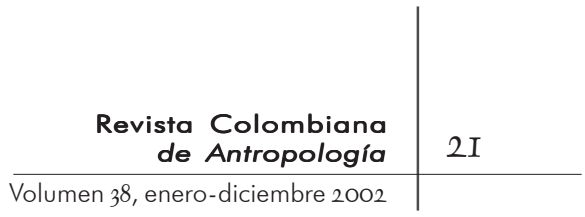

social, donde la discriminación se manifiesta en el conflicto y la violencia. En Bahía, estos dos esquemas están superpuestos: la coexistencia sobre un mismo territorio urbano y el paternalismo heredado de la época esclavista.

3. Dilema americano y nación mestiza. En la sociedad estadounidense los habitantes de las grandes ciudades del norte consideraron la llegada de las poblaciones negras del sur una amenaza, por lo que movilizaron el prejuicio racial a fin de obstruir su entrada en competición. Es el dilema americano, descrito por Gunnar Myrdal, padecido ante todo por el blanco, especialmente el pequeño blanco que socialmente está más cercano a los negros y que, consciente de tener mucho que perder en esta nueva situación de competición, refleja sobre los recién llegados sus interacciones frustradas con los otros blancos (Myrdal, I994). La lógica del análisis cambia: para entender las relaciones raciales hay que ponerse del lado de los blancos, que son quienes determinan el lugar de los negros y definen la raza negra. Pierson asegura que en Brasil los blancos jamás sintieron amenazado su estatus (Pierson, 1967: 347). Incluso el dilema americano, ese desfase entre los más altos valores de la nación y de la democracia americana y la exclusión de los negros, se resuelve -al menos ideológicamente-en América latina con el mito de la nación mestiza. Las naciones latinoamericanas al hacer referencia a esa ambigua noción de mestizaje resuelven el dilema americano de la integración.

Al substituir al negro por el mestizo Pierson y Park suponen que la asimilación es sinónimo de desaparición de las diferencias, como si la integración condujera naturalmente a la ausencia de discriminación. Al respecto, Park evoca la "tendencia, presente en Brasil, de absorber al Negro" (Park, I967: LXXIX), mientras Pierson afirma que no existe el problema negro en Bahía: "puesto que los Negros están inmersos en un proceso de absorción y serán incorporados completamente" (Pierson, 1967: 344). El problema racial tiende a ser identificado con la resistencia que un grupo en proceso de absorción ofrece o parece ofrecer (Pierson, I967: 350). Mientras que el sistema dicotómico estadounidense concluiría con la exclusión incondicional de los negros en capacidad de competir, independientemente de los méritos individuales, el régimen sudamericano ofrecería, en contraste, una gran posibilidad de movilidad y de inserción individuales, 


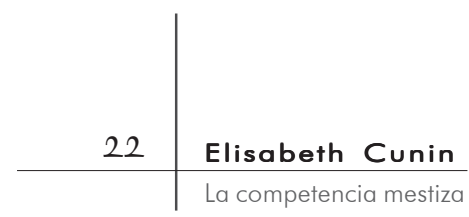

como resultado de la inexistencia del fenómeno del confinamiento detrás de una línea de color, ausencia que el mito del mestizaje simboliza.

Retomando la distinción que hacen Pierre-André Taguieff (1987; I99I) o Michel Wieviorka (I99I; I993) entre dos lógicas del racismo, una basada en un principio de inferioridad y la otra en un principio diferencialista, podríamos decir que los análisis estadounidenses tienden a aplicar una concepción diferencialista de las relaciones raciales en situaciones que están orientadas, ante todo, por una lógica de inferiorización. Parece que se razonara en el marco analítico del rechazo, del distanciamiento y de la segregación, ahí donde las prácticas responderían, más bien, a una lógica de la desigualdad, la invisibilidad y la discriminación. Por esto, un estudio que gire en torno al concepto de la asimilación no es pertinente en el caso de Bahía o de Cartagena: el individuo negro y el mestizo están integrados a la sociedad latinoamericana. El racismo está inscrito en y no ausente de las relaciones sociales. Los interrogantes deben desplazarse hacia el conocimiento del lugar que los negros ocupan y hacia cómo el factor racial interviene en su definición. El color, aun siendo un marcador físico, no es completamente indeleble; sin embargo, al estar definido socialmente no permite cualquier tipo de manipulaciones y adaptaciones. Así mismo, su producción y percepción obedecen a determinadas reglas, que no son sólo individuales. Aunque el mestizaje ofrece la posibilidad de jugar con las categorías raciales, la polarización racial -y los presupuestos biológicos sobre los cuales está basada- condiciona esta posibilidad (Agier, 2000: 228).

El juego de espejos entre América del norte y América del sur tiende a agrandar las diferencias; o mejor, impone una lógica dicotómica ahí donde habría que razonar en términos de coexistencia y entrecruzamiento. La racionalidad económica de la manumisión no pone en duda el fundamento racial de la esclavitud; el paternalismo trae consigo una polarización extrema de las relaciones socio-raciales; el mestizaje hace que integración y discriminación coexistan.

En el pensamiento estadounidense las relaciones raciales no alcanzan a ser un desafío sino hasta que se duda de la integración de los grupos raciales, a partir de una lógica intelectual no 


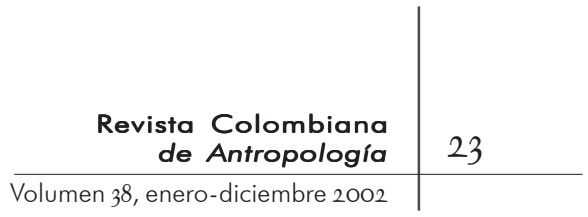

apta para pensar la cuestión racial independientemente de la de la diferenciación, ni para concebir la asimilación como algo diferente del proceso de homogeneización de las normas. Aunque en América latina las poblaciones negras han sido integradas, esto no ha impedido que sean estigmatizadas: consideradas inferiores, por tanto, discriminadas, gozan al mismo tiempo de una cierta aceptación. Para el antropólogo británico Peter Wade la única forma de resolver esta contradicción es refiriéndose a los proyectos nacionales latinoamericanos. Ante las independencias y constitución de repúblicas las elites criollas se vieron enfrentadas al problema del lugar que deberían ocupar las poblaciones negras e indígenas en las nuevas naciones y, sobre todo, al del lugar del mestizaje. Este problema no tiene equivalente dentro del proyecto nacional estadounidense. Por un lado, se trata de afirmar que el corazón de la identidad latinoamericana y su especificidad respecto de las metrópolis europeas reside justamente en el carácter mestizo de su población; por otro, el futuro de las naciones latinoamericanas, en la medida que aspire a ser sinónimo de progreso, debe pasar por el blanqueamiento de su población y, a más largo plazo, por la desaparición de los individuos negros e indios. La ideología de la nacionalidad y la mezcla de razas tiene, al final, dos aspectos: el primero, democrático, pretende que la diferencia no existe, entonces la esconde; el otro, jerárquico, se basa en la diferencia para concederle privilegios al blanco (Wade, I997: 50). Para aprehender esta coexistencia de lógicas, puede utilizarse otro concepto desarrollado por la tradición de Chicago: el del hombre marginal.

\section{El hombre marginal}

F l Individuo que posee un estatus particular, es Decir, una PO$\sqcup$ sición social definida por derechos y deberes, tiene una o varias características específicas; algunas son combinaciones que parecen ser más naturales y aceptadas que otras. Según Everett C. Hughes ${ }^{11}$, en Estados Unidos un hombre blanco y protestante será reconocido como un médico en todas las categorías sociales; no sucederá lo mismo si quien ejerce la medicina es una

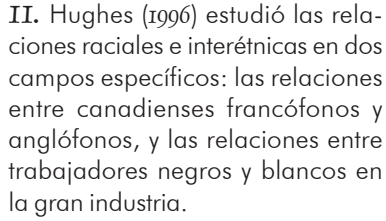

II. Hughes (1996) estudió las relaciones raciales e interétnicas en dos campos específicos: las relaciones entre canadienses francófonos y anglófonos, y las relaciones entre trabajadores negros y blancos en la gran industria. 


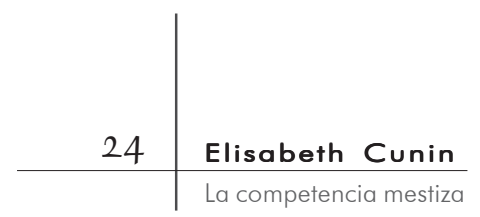

mujer negra o católica. En el primer caso, el médico posee un master status (estatus principal), en el que sus rasgos personales coinciden con las características vinculadas socialmente a la posición ocupada; en el segundo, los rasgos personales no corresponden a las expectativas, generando una confusión, un dilema de estatus. En el caso de un negro con calificación profesional, los indicios del estatus interfieren de manera contradictoria. El dilema para quien encuentre a un individuo como este será si debe considerarlo como un negro o como un profesional.

Parece como si Hughes sugiriese que la identificación racial en Estados Unidos actuara como un master status que determinaría de una vez por todas su comportamiento individual: "la pertenencia a la raza Negra, tal como se define mediante las costumbres o en las leyes americanas, puede considerarse un rasgo determinante del estatus principal. Tiende a imponerse, en la mayoría de las situaciones cruciales, sobre cualquier otra característica que pudiera oponérsele" (Hughes, 1994: 357). Entonces, uno sería negro antes que obrero o abogado, hombre o mujer, joven o viejo. Howard Becker ratifica esto cuando retoma el análisis realizado por Hughes en la descripción de los mecanismos de asignación de etiquetas en situaciones de desviación:

podemos aprovechar y tomar prestado otro elemento más del análisis de Hughes, la distinción entre estatus principal y estatus subordinado. En nuestra sociedad, y en las demás sociedades también, ciertos estatus arrastran a todos los demás. La raza es un ejemplo. La pertenencia -definida socialmente- a la raza negra prima sobre la mayor parte de consideraciones de estatus que podrían presentarse en cualquier situación (...) (Becker, I985: 56).

De igual modo que en el análisis de la desviación, las características individuales se perciben a través del prisma de la pertenencia a la categoría de negro. La identificación de un individuo como negro, o como desviado, precede a las otras identificaciones; la movilidad social y la promoción individual no cambian la categoría de pertenencia racial.

Ahora bien, aun cuando es indudable que en Estados Unidos la raza aparece como una condición necesaria y suficiente para la atribución de estatus, no puede decirse lo mismo para el caso latinoamericano, en el que la identificación racial es sólo un elemento, entre otros, de definición de la posición racial. El significado de 


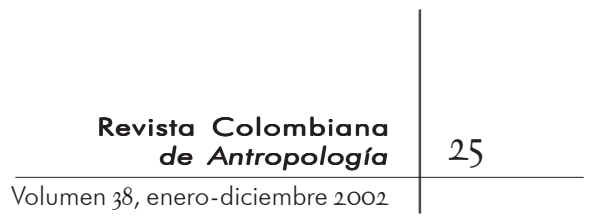

los rasgos físicos no es inflexible: las situaciones de alarma y los dilemas de estatus no son ni accidentales ni problemáticos, puesto que surgen del corazón de las prácticas cotidianas. El mestizaje no es un estado ni una cualidad, sino que, ubicado en el orden de la acción, pone en duda todo tipo de encasillamiento dentro de estatus predefinidos.

Es en este sentido que el mestizo puede ser comparado con el hombre marginal estudiado por Park y Hughes. Ambos autores llegaron a explicitar esta asociación; para Park, "el hombre marginal típico es un mestizo (mixed blood)" (Park, I950: 370); Hughes, por su parte, lo redescubre al elaborar la noción de "dilema de estatus": "La idea se encuentra en una sugestiva frase de Robert E. Park, cuando se refiere al 'hombre marginal' aplicado al caso particular del híbrido racial (...)” (Hughes, I994: 353).

La asociación entre hombre marginal y mestizo es recurrente en los trabajos de Park, especialmente en Race and Culture (I950) (véase también Stonequist, I965), en donde el mestizo está dotado de características propias del hombre marginal: inserción simultánea en dos mundos, en los que es considerado en parte extranjero (Íbid: 356); capacidad para observar con una cierta distancia los mundos de origen de sus padres (Íbid: III); rol de mediador entre las razas y las culturas (Íbid: I36); amplio horizonte que lo convierte en "el más civilizado de los humanos" (Íbid: 376), etcétera. Dos puntos merecen ser considerados con más detalle: el mestizo "ocupa una posición indeterminada entre dos culturas", y "tiene en su rostro una evidencia de su origen mestizo" (Íbid: 370). Estos elementos caracterizan al mestizaje: por un lado, estar entre dos, en el intermedio, en el intersticio; por otro, las apariencias, el cara a cara y los rasgos físicos.

Ni blanco ni negro, el mestizo -tanto como el hombre marginalse ubica en ese intermedio de la identificación, permitiéndole manipular las categorías a partir de una lógica de la no coincidencia. En efecto, los dos actúan cuestionando los mismos principios, especialmente el de identidad, en un juego que vuelve a comenzar incesantemente, y en el que cada uno de los encuentros, nunca acabados, produce nuevas reglas. En el mestizo, los signos de estatus se superponen siempre unos a otros, hasta confundir las etiquetas que determinan la relación entre posición ocupada e identidad atribuida, entre identificación social e identificación racial. Esto no significa que pueda subestimarse el peso de la discriminación y del prejuicio racial en América latina, que 
fue la tendencia más común entre los sociólogos de Chicago. Es claro que la identificación de lo negro se fundamenta en una asociación implícita con otras características, generalmente negativas. La supuesta pertenencia a la raza negra, al ser afirmada, se convierte en un estatus principal que prima sobre el resto. Pero esta atribución de estatus no es automática: si lo negro ha sido naturalizado, su identificación es un proceso dinámico y condicionado.

\section{Pensar el mestizaje}

A ATRAVESAR DE NORTE A SUR EL CONTINENTE, LOS INVESTIGADORES de Chicago invirtieron la lógica de sus razonamientos: de la egregación pasaron a la integración, de la polarización a la armonía, del modelo bi-racial al continuum. Sin embargo, otro de sus conceptos, el del hombre marginal, se impone como el más pertinente para describir el mestizaje característico de Latinoamérica: en medio de dos -o más- mundos, cotidianamente confrontado a los dilemas de estatus, el hombre marginal hace gala de esa competencia que llamaremos mestiza, para pasar de un sistema normativo a otro, para adaptar su actuación según cada situación.

\section{Un mestizaje condicionado}

F n Estados Unidos, la Categoría Negro, que designa a una Po$\sqcup$ blación variada, tiende a reducir las diferencias y los matices raciales; se habla entonces de una lógica incapaz de concebir la "palidez negra" (Pétonnet, 1986), que se explica por cuanto no han requerido entender el mestizaje (Marienstras, I976; Hollinger, I995): en efecto, cuando los investigadores estadounidenses se interesaron por el sur del continente veían en el mestizaje un símbolo de armonía social, la marca del primado de la clase sobre la raza. Según Robert Park, en América latina no existe un problema de raza (Park, I967: XXVIII). Para ello cita el caso de la sociedad brasilera, que posee la facultad de pensar la población negra, el estatus de "supervivencia arqueológica" del candomble y algunas prácticas religiosas en un contexto de asimilación. 


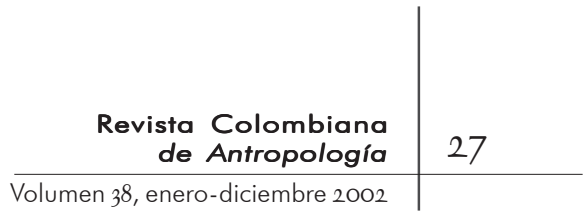

Sin duda, hay una fuerte tentación de considerar a América latina como un paraíso racial, donde la raza no sería más un freno para el ascenso social. Por ejemplo, en la sociedad brasilera los individuos alcanzan una posición social más en función de su competencia personal y del éxito individual que por su ascendencia racial (Pierson, 1967: 347). De hecho, la multiplicidad de categorías para la identificación racial existentes en Bahía es considerada como una prueba de movilidad individual. Siendo las categorías raciales tan numerosas, ¿acaso los individuos no tienen la posibilidad de combinarlas indefinidamente, y sustraerse así de cualquier asignación identitaria? Entonces ya no se trata de un problema de pertenencia racial, entendida en relación con la genética, el color o la ascendencia, sino de categorías flotantes, indeterminadas, siempre susceptibles de ser abandonadas. Sin embargo, ¿podríamos seguir a Pierson cuando afirma que las categorías de identificación cambian con cada individuo? (Pierson, 1967: XXV). ¿Podríamos considerar, como lo hacen Solaun y Kronus (1973) en su estudio sobre Cartagena, perfectamente comparable a las miradas sobre Bahía ${ }^{12}$, que el negro rico es visto como blanco y el blanco pobre como negro? ¿Podríamos razonar a partir de nociones como los gustos individuales, las preferencias reveladas por el consumidor y el mercado de las identidades, como lo hace Michael Banton al aplicar la teoría económica y el in-

I2. Las dos ciudades, antes principales puertos de llegada de esclavos al continente americano, experimentan actualmente una valorización turística que reposa, especialmente, en la puesta en escena de un multiculturalismo armonioso. dividualismo metodológico a las relaciones raciales (Banton, I97I)? ¿Podríamos afirmar que las identificaciones cambian de un individuo a otro, de un lugar a otro, de una época a otra, de una investigación a otra, de un observador a otro?

Al estudio de las relaciones raciales en América latina llegó el modelo importado de Estados Unidos, pero abandonada ya su visión dicotómica; ahora bien, este distanciamiento no debe conducir hacia un análisis simétricamente opuesto. En tal caso, se pasaría de la raza al continuum, de la barrera a la fusión, del determinismo al individualismo. De tanto insistir en la distinción respecto del paradigma de la color line, se terminan disolviendo las categorías raciales que, al ser portadoras de múltiples significaciones, pierden toda su capacidad de significación. Ciertamente, lo que la multiplicación de las categorías demuestra es la riqueza del proceso de identificación racial en Latinoamérica, que no se 


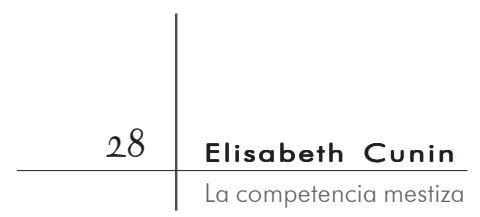

reduce a unos pocos conjuntos artificial y esquemáticamente construidos. Por tanto, retomar la multiplicidad de los términos empleados por los mismos actores, como es la tendencia de ciertos autores, es más que insatisfactorio: con el diferencialismo ${ }^{13}$

I3. De hecho, este diferencialismo se basa en la disminución de la frecuencia de aparición de algunos conceptos más comúnmente usados que otros. Para un estudio minucioso del proceso de categorización racial y étnica, ya sea por medio de la autoidentificación o de la identificación exterior, véanse los trabajos del IRD y la Universidad del Valle sobre la ciudad de Cali (Colombia), especialmente varios números de Documento de trabajo, Cidse-IRD, Cali: Universidad del Valle. absoluto se corre el riesgo de dar la espalda a la idea misma de una comunidad de experiencia y de práctica, contribuyendo, finalmente, a reproducir una estrategia de encubrimiento de las categorizaciones raciales (Agier, 2000: 198).

Ahora bien, que haya mestizaje no significa que no haya racismo; al contrario, supone una mezcla entre discriminación e integración, apoyada en el uso social de categorías raciales, y por ende, en ningún momento es borrado. La importancia que tiene el blanqueamiento en América latina es prueba de ello: se trata de adoptar los comportamientos y los modelos considerados inherentes al estatus del blanco. En otras palabras, el rechazo a identificarse y a ser identificado como negro es el único camino para ocupar una posición social valorizada en el sistema, es decir, renunciar a los atributos característicos del negro. La existencia de tal proceder muestra hasta qué punto la pertenencia racial puede actuar como un estigma que impide tajantemente el acceso a determinados estatus. Para cambiar de posición social habría que comenzar por cambiar de apariencia racial, lo cual es posible por medio del blanqueamiento, que toma formas culturales - prácticas asociadas a la cultura blanca-, sociales -ingreso a las redes blancas de sociabilidad-, o biológicas -relaciones sexuales, aclarar el color de piel, alisar el pelo-. El mestizaje no puede ser percibido como una negación del racismo: en lugar de eliminar el estigma permite convivir con él. Vale la pena recordar que en Latinoamérica el mestizaje es producto de una doble dominación, una esclavitud a la vez racial y sexual. Aunque se abre la posibilidad de escapar al handicap -o más exactamente, de aquello que se ha denominado como un handicap-, tal escape no constituye su negación.

Las nociones de hombre marginal y de dilema de estatus que Park y Hughes han introducido permiten aprehender mejor el sentido del mestizaje, que no es ni una disolución de las categorías raciales ni un encierro tras la barrera del color. Entre apariencia 


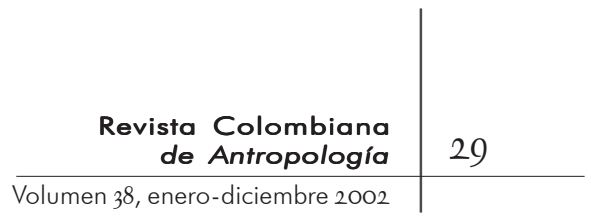

física y discurso étnico, entre asignación identitaria y manipulación de las normas, el negro no es ni un color que designa una identidad ni una máscara que pueda modificarse a gusto propio.

El empleo del término passing dentro de la literatura estadounidense (Stonequist, I965: 184-200) es revelador: consiste en pasar al otro lado del espejo, en sobrepasar la color line, y de negro convertirse a blanco. Pareciera que la pertenencia racial en cualquiera de los dos casos tuviera condiciones exclusivas. En el caso latinoamericano, el otro lado del espejo no existe y ninguna barrera se traspasa. Quizá sería más preciso decir que múltiples fronteras se superan cotidianamente. El concepto de passing no significa nada a menos que se inscriba en una práctica permanente que tomaría la forma de una ida y regreso incesantes, bien distinta de esa lógica irreversible, haciendo que los pasajes se conviertan en una actividad ordinaria y no en un cambio de estado. La calificación racial de sí mismo y la que se atribuye a los otros constantemente se modifican en el transcurso de las interacciones y se inscriben dentro de un proceso de inter-determinación en situación, yendo más allá de la sola indeterminación. El mestizaje no se sitúa en el orden de lo arbitrario ni en el de la síntesis y el desbordamiento: está hecho de ambivalencia y coexistencia, del vaivén entre normas a menudo contradictorias. El mestizaje obliga, por tanto, a renunciar a dos modos de pensamiento: primero, el analítico, concentrado en la separación, la descomposición en elementos, incluso en la pureza; luego, el de la fusión, pensamiento sintético dirigido hacia la reconciliación de los contrarios. No puede lograrse un análisis del mestizaje sólo en términos de heterogeneidad o de homogeneidad, sino que debe atenderse a su intermedio, al entre dos.

\section{Hacia una antropología de las apariencias}

A FIRMAndo la PARTICUlaridad IRREDUCTIBlE Adel caso de las poblaciones negras y asiáticas en Estados Unidos, Park ${ }^{14}$ antepone el carácter indeleble de las diferencias raciales, las consecuencias de la pertenencia a un grupo racial que no son

\footnotetext{
I4. Park dedicó una gran parte de su análisis de las relaciones raciales a los casos de los negros americanos y de los japoneses residentes en Estados Unidos. Nos remitimos es pecialmente a Park, I950, capítulos 9, "Our racial frontier on the Pacific"; II, "A race relation survey"; I4, "The race relation cycle in Hawaii"; I5, "The carreer of the Africans in Brazil"; I6, "Racial assimilation in secondary groups"; y I7, "Race prejudice and japanese-american relations".
} 


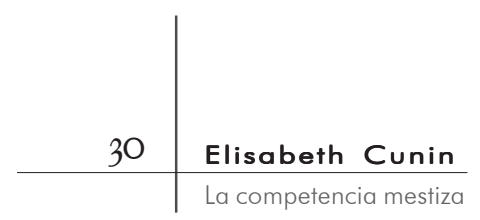

comparables, a las consecuencias de la pertenencia a grupos étnicos ligados a la migración europea. Las minorías raciales son excluidas, en efecto, de la filosofía del melting pot que integra los diferentes grupos étnicos en el país (Park, 1950) (véanse también Frazier, I949; Wieviorka, I993; Hollinger, I995). En su definición de las relaciones de raza, Park se interesa por las diferencias en los rasgos físicos que son perceptibles de manera inmediata, a las que tanto los interesados como quienes estén en contacto con ellos conceden su atención. El primer obstáculo para la asimilación de los negros o de los japoneses son sus rasgos físicos, su marca racial distintiva que pone entre las razas "el abismo de la conciencia de sí" (Park, I950: 209): "el Oriental, en parte por su manera de hablar, pero sobre todo por su color y otras características físicas, es un hombre marcado (señalado). Como el Negro, lleva un uniforme racial que no puede dejar guardado" (Park, 1950: I60).

Es interesante hacer énfasis en la siguiente paradoja: mientras dentro de la tradición estadounidense los individuos negros son definidos según un principio de ascendencia -la gota de sangre negra-, Park estudia primero que todo sus apariencias físicas. Aunque su trabajo ha sido reducido al ciclo de las relaciones raciales (Chapoulie, 1999), sus análisis llevan igualmente a reconocer la especificidad de la dimensión racial de la identificación de negro, frente a la dimensión cultural de la definición étnica de los inmigrantes que llegaron de Europa en la primera mitad del siglo veinte, y a admitir que el principal obstáculo para la asimilación del negro son sus rasgos físicos no sus rasgos intelectuales (Park, 1950: 208). Entonces, hay aquí una inversión de perspectiva: mientras se considera que la raza es una dimensión particular de la etnicidad y uno de los elementos que permite definir una identidad en forma más general, la posición de Park frente a la etnicización será vista aquí como una de las modalidades de la interacción entre individuos con rasgos raciales diferentes y no dentro de una lógica de afectación de un grupo étnico aislable.

A menudo se define la etnicidad a partir de un cierto número de criterios -idioma, religión, territorio, prácticas culturales, etcétera-, entre los cuales también se encontraría la raza (Cox, I970; Olzak, 1992). Sin embargo, hacer del grupo racial una condición previa a los grupos étnicos inscritos en la realidad social, es como si toda sociedad estuviera formada naturalmente por estos (Schnapper, 1998: 75). 


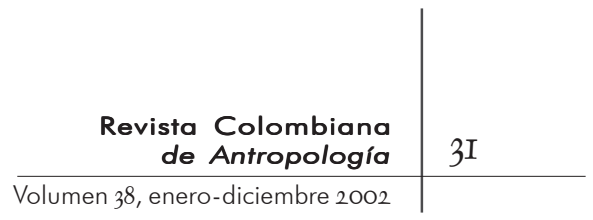

En lugar de estudiar las relaciones entre individuos de razas diferentes, Park invita a estudiar las relaciones entre individuos conscientes de la existencia de diferencias raciales y que actúan dentro de la vida social en función de dicha conciencia. Las relaciones de raza son

las relaciones que existen entre poblaciones distintas por su origen racial y, particularmente, cuando esas diferencias raciales entran a formar parte de la conciencia de los individuos y los grupos distinguidos. Así, en cada caso, determinan la concepción que el individuo tiene de sí mismo, al igual que su estatus dentro de la comunidad (...). Las relaciones de raza (...) no son exactamente las relaciones que existen entre los individuos de diferentes razas, sino las que existen entre los individuos conscientes de tales diferencias (Park, I95O: 8I) ${ }^{15}$.

Lo que es cierto en Estados Unidos lo es aún más en América latina. En el primer caso, el prejuicio racial deriva de una atribución a una categoría particular determinada por el nacimiento; en el segundo, la discriminación está fundamentada sobre todo en el aspecto personal (Banton, 197I). Mientras tanto, en América latina se observa una tendencia a reemplazar el término raza por el de color (Nogueira, I995; Hoetink, I967, I985): además de ser políticamente más correcta muestra la importancia de la apariencia en el proceso de identificación racial. No obstante, el color no contiene en sí el conjunto de elementos que intervienen en la presentación de sí y la calificación del otro: rasgos físicos -sexo, cabello, forma de nariz y boca, corpulencia, etcétera-, vestidos, entorno, contexto, etcétera ${ }^{16}$.

Tanto en su proceder científico como en la práctica, Estados Unidos han querido responder a la pregunta por la identificación de las poblaciones negras, sobre la gota de sangre. Como un verdadero principio para la definición de las poblaciones negras, esta regla inmutable identifica

I5. Park especifica que la noción de "relaciones de raza" incluye "las relaciones que, aunque no sean conscientes ni personales, alguna vez lo fueron; aquellas que han sido fijadas e impuestas por la costumbre, la convención y la rutina de un orden social sobre el cual, en un momento dado, podría no existir una conciencia suficientemente lúcida" (Park, 1950: 83).

I6. Fenómeno que se encuentra en el Caribe insular, como atestigua, por ejemplo, este extracto de la novela de Patrick Chamoiseau, Texaco: "María-Sofía, no hay que creer, estaba el asunto del color pero también el asunto de los modales y des beaux airs. Con los modales y las buenas maneras te veían mulato, pese a que todos los mulatos eran algunas veces negros. Pero un mulato de piel (sin hablar siquiera del blanco) se quedaba tal y como era si no tenía los modales y las buenas maneras. Es complicado pero es la verdad: los mejores modales eran tener una piel sin el color de la esclavitud" (Chamoiseau, 1992: 95). 


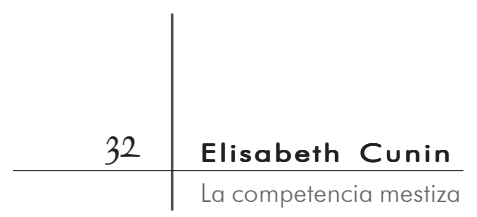

I7. Sucede lo mismo en África del Sur, donde se habla del test del peine. Por tanto, más allá de las reglas ampliamente admitidas, las dificultades para realizar censos étnicos en África del Sur-existencia de la categoría gentes de color-, y en Estados Unidos -con la introducción del rubro mixed-blood-, reflejan la incertidumbre que hay en torno a las definiciones étnicas. Sobre África del Sur, véase Borenstein (I987: II6-I2I). Sobre Estados Unidos, Diouf-Kamara (I993: 30); Hollinger (I995: I, 45). Véase también la multiplicación de categorías que se introdujeron en el censo de 2000 en Estados Unidos.

una lógica relacional y situacional. Ahora bien, si el principio de la lón de las interacciones cotidianas en Estados Unidos, como lo muestran los análisis de Park, esto no impone que en América latina haya una tendencia a definirse en oposición a dicha lógica, como se observa en Brasil y en Colombia.

¿Qué es ser ‘blanco’? ¿Qué es ser ‘negro’? ¿Qué es ser de ‘color’? Estas denominaciones, para el sentido común, parecen evidentes, pues se refieren a realidades biológicas que se imponen por sí solas (...) Esto es ser víctima de una ilusión: se trata de categorías cognitivas que, a partir de nuestra percepción de las diferencias visibles en el espectro físico, son claramente heredadas de la historia de la colonización (Bonniol, I992: II).

Para responder a estas preguntas hay que comprender cómo los atributos biológicos son interpretados socialmente, cuáles son los códigos sociales que rigen la referencia a la raza, cuáles las normas de comportamiento que integran la diferencia racial, cuáles las convenciones a las que se adhieren los individuos. Tomarse en serio el papel de las apariencias físicas es alejarse también de la tendencia actual a diagnosticar un "racismo sin raza”, tal como lo describe Etienne Balibar (Balibar y Wallerstein, I990: 32-33): el aspecto predominante no sería más la herencia biológica sino la irreductibilidad de las diferencias culturales -que funcionarían entonces, paradójicamente, como una verdadera naturaleza-. Ante este racismo culturalista se trata de privilegiar el estudio de las interacciones entre lo biológico y lo 


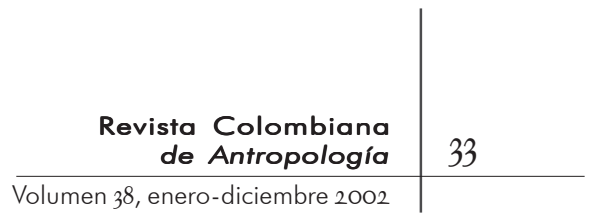

social, revaluando el alcance social y epistemológico de las apariencias físicas -raza, aunque también sexo, edad, altura, desventajas, etcétera-, primer elemento de evaluación del otro y de presentación de sí mismo.

Goffman lo ha expresado bastante bien: "la naturaleza más profunda está a flor de piel" (I973: 338$)^{18}$. Hay que interesarse entonces por la manera como los individuos perciben sus apariencias mutuas, combinando la evaluación individual con la movilización de las normas sociales. De las imprecisiones cometidas en este proceso los individuos adquieren su capacidad para modificar su presentación, para negociar las expectativas recíprocas, para adaptarse a una situación particular. Los rasgos raciales representan tantos elementos en el repertorio del individuo y tantos factores de decisión para los otros, que se esfuerzan en asignarle un papel (Douglass y Lyman, I976: 2I8). No se trata entonces de ir a buscar la verdad más allá de lo que puede ser visto sino de descubrir la profundidad de la superficialidad, interesándonos en unas apariencias cuya gestión se fundamenta en la capacidad de los individuos para calificar la situación, responder a las expectativas y posicionarse, para interpretar las convenciones del encuentro y movilizar un saber socio-histórico a menudo difuso e implícito.

\section{Competencia mestiza}

I A IDENTIFICACIÓN RACIAL NO ES NI ESENCIAL $\longrightarrow$ ni opcional: es situacional. Isaac Joseph, al presentar la sociología de Erving Goffman, se refiere a la noción de "competencia"19, que define la capacidad de enfocar el evento, movilizar los conocimientos previos e interpretar la trayectoria de la acción (Joseph, I998: IO3). De ello se deduce que las formas concretas de la negociación en situaciones de contacto -evocando una vez más la clásica problemática de la integración o la inserción- no están ligadas únicamente a la identidad social y cultural de los individuos, sino también a su capacidad
I8. Vale la pena comparar esta frase con una afirmación de Nina de Friedemann, según quien el objetivo de la antropología es buscar las huellas de africanía más allá de las apariencias: "El reto de la afroamericanística ha sido entonces encontrar no la máscara, sino al enmascarado" (de Friedemann, I993: 170)

I9. Noción que surge de los trabajos de sociolingüística interaccional desarrollados por John Gumperz (I989) y Dell Hymes (I984), especialmente en lo relacionado con la "conmutación de código" (code switching), como competencia social de los actores que pertenecen a comunidades de lengua diferentes. El bilingüismo genera problemas por suponer la pluralidad de códigos y su coexistencia en el transcurso de la interacción. 


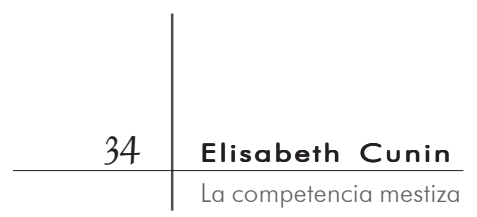

para evaluar los parámetros de la interacción, movilizar las normas apropiadas y realizar una hazaña adaptada. Gracias a su competencia, los individuos comprometidos en la interacción saben identificar, dentro de determinado contexto, los indicios que les permitirían jerarquizar las responsabilidades y las prácticas, enmarcar las expectativas basadas en su experiencia previa y evaluar los recursos a los que tienen acceso durante la interacción.

La competencia mestiza ${ }^{20}$ corresponde justamente a esa capacidad de jugar con el color y su significación, de contextualizar las apariencias raciales con el fin de

20. Véase también R. Bastide y su "principio de corte" (Bastide, 1996). adaptarse a las situaciones, de pasar de un espacio de normas a otro. Esta capacidad no se despliega en un espacio social sin restricciones, indeterminado: al contrario, reposa sobre la facultad de conocer y adaptar los códigos. Coincide con lo dicho por Carmen Bernand y Serge Gruzinski a propósito de la época colonial:

la generalización de los mestizajes acostumbra a los individuos y a los grupos más expuestos a circular entre las culturas y los modos de vida. Estos ires y venires desarrollan una sensibilidad cultural hacia la diferencia, una aptitud para variar los registros, al igual que estimulan la capacidad para mezclarse o para multiplicar las máscaras y las pertenencias (Bernand y Gruzinski, I993: 622).

La competencia mestiza moviliza, a la vez, la presentación de aquello que, de manera más o menos intencional, está hecho para ser leído por el otro, y la atribución de un estatus y unas expectativas relacionales que, además, recaen también sobre el otro. Entonces, está basada en una interpretación mutua de los signos percibidos y en el hecho de compartir los mismos presupuestos cognitivos, convencionales y vulnerables.

Para Goffman, la pertenencia racial hace parte de los estigmas (Goffman, 1975: I4). Pero hay que tener cuidado con el estigma, que esconde dos puntos de vista:

¿Asume el individuo estigmatizado que su diferencia es conocida o visible al instante, o más bien piensa que no es ni conocida ni inmediatamente perceptible para las personas presentes? En el primer caso, debe considerarse como una especie de individuo desacreditado; en el segundo, como la de un individuo desacreditable (Goffman, I975: I4. Subrayado por el autor). 


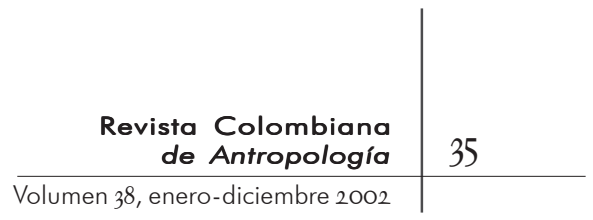

Partiendo de esta definición, parecería lógico considerar al negro como un individuo desacreditado, dado que su fenotipo se caracteriza justamente por su visibilidad inmediata y el color de su piel por ser una marca indeleble. No obstante, la situación encontrada en Cartagena corresponde más a los análisis del individuo desacreditable, en el sentido de Goffman. La raza es una condición necesaria pero insuficiente para la estigmatización. Aunque el negro es, en general, una categoría estigmatizada, el individuo negro se concibe, tanto en el discurso como en la práctica, como una víctima potencial y no efectiva del racismo, pues tiene la capacidad de jugar con los signos de su estigma, con frecuencia atenuándolos y algunas veces exhibiéndolos. El propio Goffman dice, respecto del individuo desacreditable, que "el problema no reside en saber manejar la tensión generada por las relaciones sociales, sino en saber manipular la información relativa a una deficiencia: exponerla o no, expresarla o no, guardar o no las apariencias, decir o no mentiras, y además, en cada caso, a quién, cómo y cuándo" (Goffman, I975: I3).

Goffman precisa que: "la palabra estigma servirá para designar un atributo que arroja un descrédito profundo, aunque debe advertirse que, en la realidad, conviene hablar en términos de relaciones y no de atributos" (Goffman, I975: I3). En síntesis, el estigmatizado y el normal no son personas sino puntos de vista; la estigmatización depende, entonces, de lo que se supone que el otro es: el estigma, su atribución o su rechazo, está vinculado al saber práctico de los individuos que se movilizan en el marco de la interacción. Este es el motivo por el que el estigmatizado se ha convertido en un maestro en el arte de las falsas apariencias, controlando la información destinada a los otros (Goffman, I975: 99; Martuccelli, I999: 450).

Así, uno podría decir que no existe una identidad de género. Lo que existe es un programa para realizar el retrato del género (...). La única evidencia disponible es la coreografía del retrato de las relaciones entre los sexos. Pero sobre lo que más concretamente nos hablan estos retratos no es del género ni de las relaciones generales entre los sexos, sino del carácter específico y el funcionamiento del retrato (Goffman, I979: 8. Subrayado por el autor).

Lo mismo que sugiere Goffman con respecto al género puede aplicarse para abarcar los mecanismos mediante los que se construyen, 


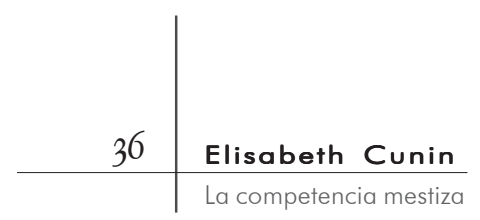

conocen y adoptan las convenciones raciales, concebidas como elementos del cara a cara con el otro. Los actores manipulan y se adhieren a códigos que les permiten interpretar el comportamiento de los otros y adoptar ellos mismos la actitud más apropiada. Lejos de estudiar las diferencias entre individuos negros, blancos o mestizos el objetivo debe ser analizar su capacidad para movilizar, instrumentalizar y negociar las normas de actuación, conservando únicamente su dimensión racial.

De hecho, estos ajustes se aplican también al encuentro con los otros y otorgan la capacidad de ennegrecer a los individuos que ocupan un estatus social considerado inferior, y blanquear aquellos que ocupan una posición superior. En este sentido, la competencia puesta en acción por el más negro de los individuos -estatus otorgado en una situación particular- es a la vez más limitada y más extensa: limitada en cuanto al universo de posibilidades tanto en la presentación de sí como en la evaluación del otro; extensa en la medida en que sus entradas/salidas necesiten de cambios normativos radicales.

Evitación y atenuación de la dimensión racial en las situaciones cotidianas, respetando las normas ordinarias y los marcos de la experiencia; lógica de etnicización, como parte de un movimiento de afirmación de la diferencia y de instrumentalización del multiculturalismo naciente; etiquetaje racial de la desviación y construcción del estigma; manipulación de las convenciones, juego de rostros y de fachadas, recurrencia del desfase identitario: así pues, la competencia mestiza abre la vía para el estudio de la gestión, relacional y situacional, de las apariencias raciales, de las modalidades en que se construye, se adapta y se invierten las normas raciales ${ }^{21}$.

Con base en lo anterior, podemos in-

2I. Sobre el empleo de esta competencia mestiza en el estudio de las relaciones y normas raciales a partir del análisis de cuatro escenarios urbanos, me permito remitir a mi tesis doctoral de sociología, cuyo tema es la ciudad de Cartagena, en la costa Caribe colombiana (Cunin, 2000). incluso presentes desde comienzos del siglo veinte. De hecho, la introducción oficial del multiculturalismo no ha originado los movimientos de reivindicación étnica más importantes, especialmente en los casos de la costa caribe colombiana y 


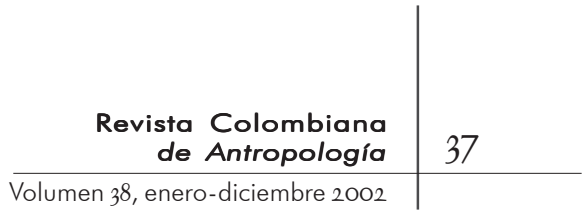

venezolana. Resulta más fácil escapar al estigma haciéndose pasar como menos negro que el otro, tanto en el discurso como en la práctica, en lugar de militar a favor de una hipotética causa negra. Si los individuos negros estadounidenses no pueden integrarse y ascender sino por medio de la reivindicación de un sistema social paralelo, por su parte, el latinoamericano, al disociarse del más negro, dirige el peso del racismo hacia otro, presente o imaginario. Aquí, la movilidad social no es conflictiva, puesto que, por definición, el mestizo es aquel que siempre está en movimiento dentro de un espacio, limitado social y racialmente por dos polos, uno negro y otro blanco. Este, además, es un trabajo de figuración que no es ni una gestión racional y calculada de las apariencias ni la imposición de una máscara perpetua. La competencia mestiza permite negociar el color en un juego infinito de entradas y salidas en el que la presentación de sí se hace bajo el control del otro y de acuerdo con un marco normativo que rige la interpretación de una situación y el compromiso de los actores. En este sentido, la introducción del multiculturalismo tiende a reducir el ejercicio de esta competencia mestiza al transformar las identificaciones confusas y flotantes en identidades étnicas fijas y pre-definidas ${ }^{22}$.

\section{CONCLusión}

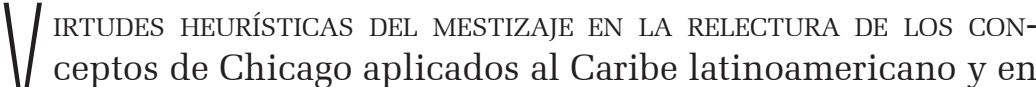
los análisis de la fluidez y la multiplicidad de las identificaciones y de las interacciones. Más allá del mito de la democracia racial es preciso recordar que el mestizaje nació entre las violaciones y la esclavitud. No basta pues con la sola existencia del mestizaje que, en tanto que paradigma de una sociedad igualitaria, favorece la atenuación del estigma; además, está la posibilidad de encontrar a alguien más negro que uno. Las sociedades latinoamericanas hacen del más negro una categoría, real o simbólica, inferiorizante y negativa: la existencia de este estigmatizado/estigmatizable, siendo

22. En Colombia, la introducción del multiculturalismo ha generado dos procesos inversos: una fuerte instrumentalización de las nuevas leyes étnicas en la región del Pacífico, que tiene varias consecuencias políticas y sociales (Agier y Hoffmann, I999); o una ignorancia o un rechazo a estas leyes, asimilable a una lógica de racismo invertido, como en el caso de la costa Atlántica (Cunin, 1999). 


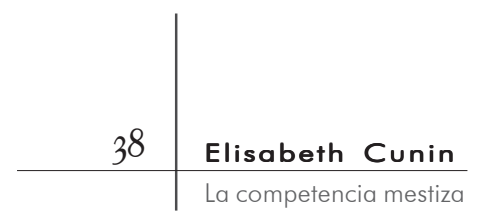

a la vez absoluto y relativo, es la que permite que cada quien escape, por sí mismo, de la estigmatización, en contra de una supuesta armonía racial, tal como la pensaba la tradición de Chicago. El hecho de tomar en cuenta el elemento racial en las relaciones sociales -al menos en Colombia y Brasil y, en general, en el área caribeña- no sólo es el signo de una patología, como sugeriría la asociación recurrente entre racismo y lucha contra el racismo (Taguieff, I987, I99I; Wieviorka, I992); además, debe entenderse como un principio de organización del cuerpo social (Bonniol, I990: 4IO).

Virtudes heurísticas del mestizaje, de otro lado, que inauguran dos orientaciones divergentes en el marco de la investigación. La primera tomaría en serio el rol de las apariencias durante la interacción: ¿cómo presentan los actores sociales sus diferencias físicas? ¿Cuál es su papel en las prácticas sociales? ¿Cómo están articuladas con los diferentes procesos de pertenencia social? En cierto modo, una temática como esta es más susceptible que otras de incorporar los estereotipos; en consecuencia, permite iluminar la producción y el mantenimiento de las normas que rigen las relaciones sociales y, más allá, los propios mecanismos de emergencia y consolidación de las reglas sociales en su conjunto. Conduce, pues, a intentar abarcar los procesos mediante los cuales se construyen, se conocen y se adoptan las convenciones en torno a la aprehensión social de lo biológico, concebidas como elementos del cara a cara con el otro.

La segunda orientación tendería a extender la noción de competencia mestiza por encima de una aprehensión biológica del mestizaje. Capacidad para jugar con las apariencias y sus significados, para adaptarse a las situaciones, para pasar de un determinado espacio de normas hacia otro, la competencia mestiza se despliega, precisamente, cuando se realiza una actuación adaptada. Es una facultad de interpretar, movilizar y negociar que, por tanto, trasciende el nivel de la sola identificación $r a-$ cial. El análisis presentado gira en torno a la relación negro/blanco; sin duda, sería interesante preguntarse qué acontece para otro tipo de mestizajes en América latina -por ejemplo, la relación indígena/blanco- o en Europa. El uso de la noción de competencia mestiza podría ampliarse también al abordar aspectos como el de la "urbanidad mestiza" (Baby, 2000) o el de las formas de movilidad circular (Chivallon, I997), que han sido planteados con base en esa misma capacidad para conciliar prácticas 


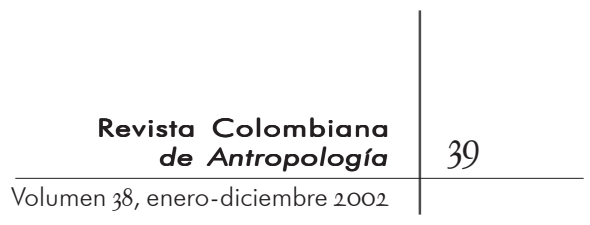

contradictorias: por un lado, marginalidad y urbanidad, movilidad y segregación, formal e informal, rural y urbano; por el otro, multiplicación de los territorios referenciales y de las filiaciones identitarias, procesos de ida y vuelta, posicionamiento entre dos, entre el aquí y el allá.

\section{BibliOgRAFÍA}

Agier, Michel. 200o. Anthropologie du carnaval. La ville, la fête et l'Afrique à Bahia. Editions Parenthèse-IRD. Marsella.

Agier, Michel, Hoffmann, Odile, I999. "Les terres des communautés noires dans le Pacifique colombien. Interprétation de loi et stratégie d'acteurs". Problèmes d'Amérique Latine. 32. Enero-marzo.

Agudelo, Carlos Efrén. 1999. "Colombie: changement constitutionnel et organisation des mouvements noirs”. Problèmes d'Amérique latine. 32. Enero-marzo.

Amselle, Jean-Loup. 1990. Logiques métisses. Anthropologie de l'identité en Afrique et ailleurs. Payot. París.

. I999. "Black, blanc, beur ou le fantasme du métissage".

En S. Kandé (dir.). Discours sur le métissage, identités métisses. En quête d'Ariel. L'Harmattan. París.

- 2000. "Le métissage: une notion piège". Sciences Humaines. IIo. Noviembre.

Baby, Virginie. 2000. "Marginaux et citadins. Construire une urbanité métisse en Amérique latine. Etude comparée des barrios de Caracas (Venezuela) et des villas d'El Alto de La Paz (Bolivie)". Thèse de doctorat de géographie (dir. C. Bataillon et J. Monnet). Université de Toulouse 2, I9 décembre.

Balibar, Etienne, Wallerstein, Immanuel. I990. Race, nation, classe. Les identitiés ambigües. Edition La Découverte. París.

Banton, Michael. 197i. Sociologie des relations raciales. Payot. París (1967).

- 1986. "Epistemological assumptions in the study of racial differentiation”. En J. Rex, D. Mason. Theories of race and ethnic relations. Cambridge University Press. Cambridge.

Bastide, Roger. 1996. Les Amériques Noires. L’Harmattan. París.

BeCKer, Howard S. (1963) 1985. Outsiders. Etudes de sociologie de la déviance. Métailié. París. 
. 1998. La soi-disant Ecole de Chicago. Colloque Université de Versailles Saint Quentin en Yvelines. 3 de abril.

Benoist, Jean, Bonniol, Jean-Luc. i994. "Hérédités plurielles. Représentations populaires et conceptions savantes du métissage". Ethnologie Française. Tomo 24. Enero-marzo.

Bernard, Carmen, Gruzinski, Serge. i993. Histoire du nouveau monde. Les métissages, Fayard. París.

Bonniol, Jean-Luc. I990. "La couleur des hommes comme principe d'organisation sociale". Ethnologie Française. Tomo 20. Octubrediciembre,

- I992. La couleur comme maléfice. Une illustration créole de la généalogie des Blancs et des Noirs. Albin Michel.

Borenstein, Richard. 1987. "Les "gens de couleur" au pays de la différence obligatoire”. En Vers des sociétés pluriculturelles: études comparatives et situation en France. Editions de l'ORSTOM. París.

Bouysse-Cassagne, Th. 1994. "Incertitudes identitaires métisses: l'éloge de la bâtardise". Caravelle. 62.

Cabellos Barreiro, Enrique. ig9i. Cartagena de Indias. Mágica acrópolis de América. Colegio de Ingenieros de Caminos, Canales y Puertos-Centro de Estudios y Experimentación de Obras Públicas-Cedex-Cehopu. Madrid.

Chamoiseau, Patrick. i992. Texaco. Folio Gallimard. París.

Chapoulie, Jean-Michel. 1999. "Robert E. Park, étude des relations entre les races". Sociétés Contemporaines. 33/34. Enero-abril.

- 200I. La tradition sociologique de Chicago: I862-I96r. Le Seuil. París.

Charier, Alain. 200o. Le mouvement noir au Venezuela: revendication identitaire et modernité. L'Harmattan. París.

Chivallon, Christine. I997. "De quelques préconstruits de la notion de diaspora à partir de l'exemple antillais". Revue Européennes des Migrations Internationales. I3.

Cox,Oliver C. (I948) I970. Caste, class and race. A study in social dynamics. Modern Reader Paperbacks.

Cunin Elisabeth. 1999. "Relations interethniques et processus d'identification à Carthagène". Cahiers des Amériques Latines. 33.

- 2000. "Le métissage dans la ville. Apparences raciales, ancrage territorial et construction de catégories à Cartagena (Colombie)". Tesis de doctorado de sociología (director Yvon Le Bot). Université Toulouse 2. 29 de noviembre 2000. (Próxima edición en español, ICANH). 


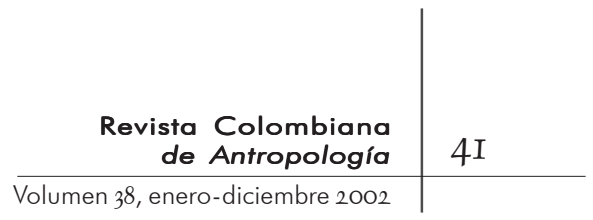

Davis, F. James. I99I. Who is black? One Nation's definition. Pennsylvania State University Press. University Park.

Degler, Carl N. I97i. Neither black nor white. Slavery and race relations in Brazil and the United States. The University of Wisconsin Press. Madison.

Diouf-Kamara, Sylviane. I993. "USA: à la recherche d'une troisième voie”. Hommes et migrations. iı6r. Enero.

Douglass, William, Lyman Stanford. I976. "L'ethnie: structure, processus, saillance”. Cahier International de Sociologie. Volumen LXI.

Doyle, BerTRAm Wilbur. I937. The etiquette and race relations in the South: a study in social control. The University of Chicago Press. Chicago.

Du Bois, William, E. Burghardt. i899. The Philadelphia Negro: a social study. The University of Pensylvania Press. Philadelphia.

Frazier, E. Franklin. 1949. The Negro in the United States. The Mac Millan Company. Nueva York.

Freyre, Gilberto. 1997. Maîtres et esclaves: la formation de la société brésilienne. Gallimard. París.

De Friedemann, Nina. I993. "La antropología colombiana y la imagen del negro”. América Negra. 6. Diciembre.

Goffman, Erving. 1973. La mise en scène de la vie quotidienne. Tome I: la présentation de soi. Les Editions de Minuit. París.

- 1974. Les rites d'interaction. Les Editions de Minuit. París. . (1963) 1975. Stigmate. Les usages sociaux des handicaps. Les Editions de Minuit. París.

- 1979. Gender advertisement. Harper Torchbooks. Nueva York.

- (1974) 1991. Les cadres de l'expérience. Les Editions de Minuit. París.

Gruzinski, Serge. I999. La pensée métisse. Fayard. París.

Gumperz, J. 1989. Engager la conversation. Les Editions de Minuit. París.

Hannerz, Ulf. 1980. Explorer la ville. Eléments d'anthropologie urbaine. Les Editions de Minuit. París.

Harris, Marvin. 1965. Patterns of race in the Americas. Walker and Co. Nueva York.

Hoetink, Harry. 1967. The two variants in the Caribbean race 
relations: a contribution to the sociology of segmented societies. Oxford University Press. Londres, Nueva York y Toronto.

Hoetink, Harry. 1985. “"Race” and color in the Caribbean”. En S. W. Mintz, S. Price. Caribbean Contours. The Johns Hopkins University Press. Baltimore y Londres.

Hollinger, D. A. ig95. Postethnic America. Beyond multiculturalism. Basic Books. Nueva York.

Hughes Everett, Cherrigton. I994. "Dilemmas and contradiction of status". The American Journal of Sociology. Volumen L: I. Julio.

- 1996. Le regard sociologique. Essais choisis. Textes rassemblés et présentés par J. M. Chapoulie. Editions de l'EHESS. París.

Hymes, Dell. 1984. Vers la compétence de communication. Hatier. París.

Jaramillo Uribe, Jaime. I994. Ensayos de historia social. Tomo I. La sociedad neogranadina. Tercer Mundo Editores-Ediciones Uniandes. Bogotá.

Joseph, Isaac. 1998. Erving Goffman et la microsociologie. PUFPhilosophies. París.

Laplantine, François, Nouss, Alexis. 1997. Le métissage. Dominos, Flammarion. París.

Le Bras, Hervé. I998. Le démon des origines; démographie et extrême droite. Editions de l'Aube. La Tour d'Aigues.

Lovell, Peggy A. 1994. "Race, gender and development in Brazil". Latin American Research Review. Volumen 29: 35.

Marienstras, Elise. 1976. Les mythes fondateurs de la nation américaine. Essai sur le discours idéologique aux Etats Unis à l'époque de l'indépendance (I763-1800). François Maspero. París.

Martuccelli, Danilo. I999. Sociologies de la modernité. Folio-Essais. París.

Myrdal, Gunnar. 1994. An American Dilemma. The negro problem and modern democracy. Volumen I. Harper and Brothers Publishers. Nueva York y Londres (1944).

Nogueira, Oracy. 1995. "Preconceito racial de marca e preconceito racial de origem". Anais do XXXI Congreso Internacional de Americanistas. Volumen I. Ed. Anhembi. Sao Paulo.

Olzak, Suzan. I992. The dynamics of ethnic competition and conflict. Stanford University Press. California.

Park, Robert Ezra. 1950. Race and Culture. The Collected Papers 


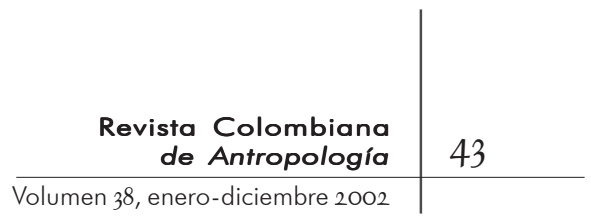

of Robert Ezra Park. Volumen I. The Free Press. Glencoe (Illinois).

. (1942) I967. "Introduction". En D. Pierson. Negroes in Brazil. A study of race contact at Bahia. Southern Illinois University Press. Carbondale y Edwardsville. Feffet and Simons Inc. Londres y Amsterdam.

Petonnet, Claudette. I986. "La pâleur noire. Couleur et culture aux Etats-Unis”. L'Homme. XXVI ${ }^{\mathrm{e}}$ année. 97-98. Enero-junio.

Pierson, Donald. (1942) 1967. Negroes in Brazil. A study of race contact at Bahia. Southern Illinois University Press. Carbondale y Edwardsville. Feffet and Simons Inc. Londres y Amsterdam.

- 1972. "Brazilians of mixed racial descent". En N. P. Gist, A. G. Dworkin. The blending of races. Marginality and identity in world perspective.Wiley Interscience. Nueva York.

Pitt-Rivers, Julian. I973. "Race in Latin America: the concept of “raza”". Archives Européennes de Sociologie. Tomo XIV: I.

Population. I998. 3. Mayo-junio. Dossier sur "la variable "ethnie" comme catégorie statistique".

REDField, Robert. I958. "Race as a social phenomenon". En E. T. Thompson, E. C. Hughes (editores). Race. Individual and collective behavior. The Free Press. Glencoe.

Sala-moulins, Louis. 1992. L’Afrique aux Amériques. Le Code Noir espagnol. PUF. París.

Schnapper, Dominique. I998. La relation à l'autre. Au cœur de la pensée sociologique. Gallimard, Essais. París.

Solaun, Mauricio, Kronus, Sidney. 1973. Discrimination without violence. Miscegenation and racial conflict in Latin America. John Wiley and Sons. Nueva York, Londres, Sidney, Toronto.

Spickard, Paul R. 1989. Mixed blood: intermarriage and ethnic identity in twentieth-century America. Madison.

SKidmore, Thomas. 1993. "Bi-racial USA vs multiracial Brazil: is the contrast still valid?". Journal of Latin American Studies. Vol. 25, part 2. Mayo.

Stonequist, EveretT V. 1965. The marginal man. A study in personality and culture conflict. Russell and Russell (1937). Nueva York.

TAguiefF, Pierre-André. I987. La force du préjugé. Essai sur le racisme et ses doubles. La Découverte. París.

. 1991. Face au racisme. Le moyen d'agir. Tomo i. La Découverte. París. 
Tribalat, Michèle. 1996. Avec la participation de Patrick Simon y Benoît Riandey. De l'immigration à l'asimilation. Enquête sur les populations d'origine étrangère en France. La Découverte/ INED. París.

Uribe, María Victoria, Restrepo, Eduardo (editores). I997. Antropología en la modernidad: identidades, etnicidades y movimientos sociales en Colombia. ICAN. Bogotá.

Vasconcelos, José. 1992. Obra selecta. Biblioteca Ayacucho. Caracas.

VERAn, JEAn-François. I999. "Brésil: la découverte du quilombo. La construction hétérogène d'une question nationale”. Problèmes d'Amérique latine. 32. Enero-marzo.

Wade, Peter. I997. Gente negra, nación mestiza. Dinámicas de las identidades raciales en Colombia. Editorial Universidad de Antioquia-ICAN-Siglo del Hombre Editores-Ediciones Uniandes. Bogotá.

Wagley, Charles. I968. The latin American tradition. Columbia University Press. Nueva York y Londres.

Wieviorka, Michel, I99I. L'espace du racisme. Seuil. París.

— . 1992. La France raciste. Seuil. París.

. I993. La démocratie à l'épreuve. Nationalisme, populisme, ethnicité. La Découverte, Essais. París. 